\title{
Engineering Electrostatic Repulsion of Metal Nanoparticles for Reduced Adsorption in Single-Impact Electrochemical Recordings
}

\author{
Lennart J. K. Weiß ${ }^{\dagger}$, Emir Music ${ }^{\dagger}$, Philipp Rinklin ${ }^{\dagger}$, Lea Straumann ${ }^{\dagger}$, Leroy Grob ${ }^{\dagger}$, Dirk Mayer, Bernhard Wolfrum ${ }^{*},+$ \\ ${ }^{+}$Neuroelectronics, Munich School of Bioengineering, Department of Electrical and Computer Engineering, \\ Technical University of Munich, 85748 Garching, Germany \\ ${ }^{\ddagger}$ Institute of Biological Information Processing, Bioelectronics (IBI-3), Forschungszentrum Jülich, 52425 Jülich, Germany \\ *Corresponding Author: Bernhard Wolfrum, bernhard.wolfrum@tum.de
}

\section{Open Circuit Potential of a Floating Shield Electrode}

We measured the open circuit potentials (OCP) of the floating Pt shield electrode against Ag/AgCl before and after the insertion of AgNPs as shown in Fig. S1. First, the OCP of the floating shield electrode in $25 \mathrm{mM} \mathrm{KCl}$ was recorded for $180 \mathrm{~s}$. Then, the OCP after insertion of AgNPs was measured for $300 \mathrm{~s}$. We found the OCP to be $209 \pm 4 \mathrm{mV}$ (mean, standard deviation) in a pure electrolyte solution. After the insertion of AgNPs, we observe a drastic change of $\sim 120 \mathrm{mV}$ within the time of a typical experiment. Finally after $10 \mathrm{~min}$, the OCP was measured again for $300 \mathrm{~s}$ and reached a constant value of $-154 \pm 3 \mathrm{mV}$.

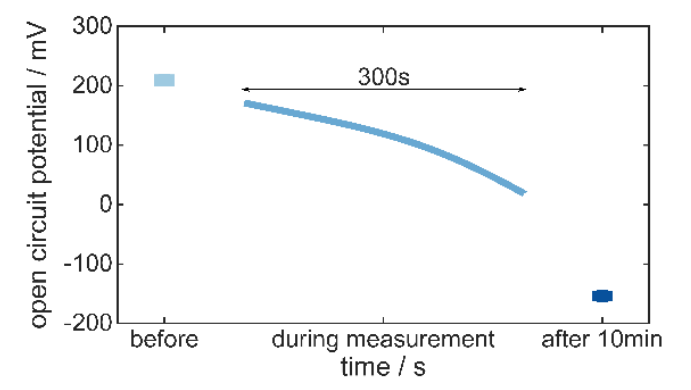

Figure S1 OCP of a floating Pt shield electrode during a detection experiment with $43 \mathrm{pM}$ of $20 \mathrm{~nm}$-AgNP in $25 \mathrm{mM} \mathrm{KCl}$ solution. Error bars (before, after $10 \mathrm{~min}$ ) indicate standard deviations.

\section{Anodic Stripping Voltammetry of a Shield Electrode}

We investigated the electrodeposition of $\mathrm{Ag}^{+}$ions on the shield electrode being held at $-200 \mathrm{mV} \mathrm{vs} \mathrm{Ag} / \mathrm{AgCl}$ during an anodic stripping voltammetry experiment. To this end, we exchanged the electrolyte after the experiment and applied a linear sweep from $0 \mathrm{mV}$ to $800 \mathrm{mV}$ vs $\mathrm{Ag} / \mathrm{AgCl}$ with a scan rate of $100 \mathrm{mV} / \mathrm{s}$ after an initial phase with $5 \mathrm{~s}$ at $-200 \mathrm{mV}$ and $2 \mathrm{~s}$ at $0 \mathrm{mV}$. We compared the results to a clean chip, see Fig. S2, and did not find a significant difference indicating the presence of $\mathrm{Ag}^{+}$ions. This can probably be explained by the limited mass transport of oxidized species towards the shield electrode within the time scale of our experiment.

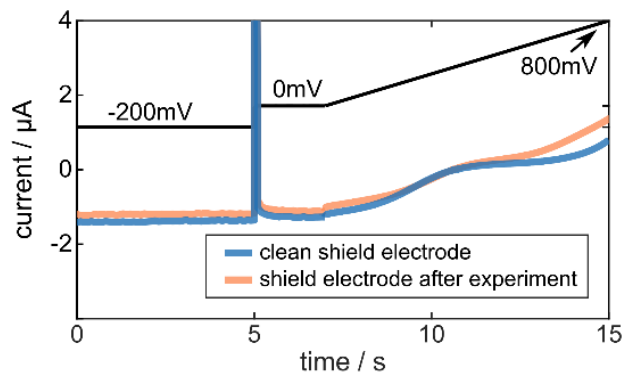

Figure S2 Anodic stripping voltammetry of a shield electrode directly after the detection experiment (red) compared to a cleaned shield electrode (blue). The potential was first held at $-200 \mathrm{mV}$ and after $2 \mathrm{~s}$ at $0 \mathrm{mV}$ swept to $800 \mathrm{mVvs} \mathrm{Ag} / \mathrm{AgCl}$ with a scan rate of $100 \mathrm{mV} / \mathrm{s}$. 


\section{Statistical Information on Amplitudes, Durations and Charge of AgNP Impacts for Different Passivation Conditions}

Fig. S3 provides statistical information about the amplitudes, the durations and the charge of all considered peaks that have been used in Fig. $2 \mathrm{~d}$, e, and $\mathrm{f}$ for further analysis.
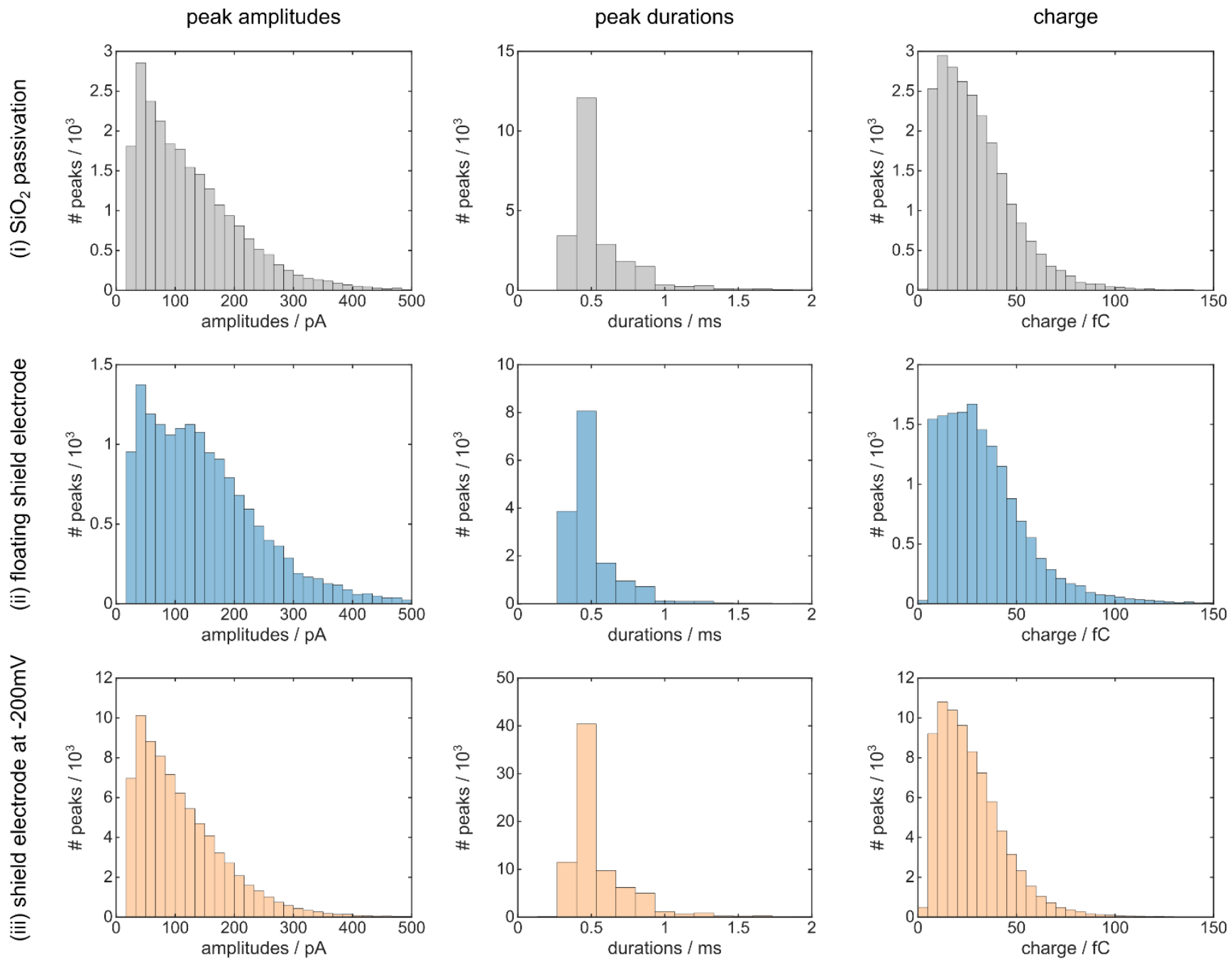

Figure S3 Statistical information on amplitudes, durations and charge of all considered current peaks for the experimental conditions of (i) a $\mathrm{SiO}_{2}$-passivated chip, (ii) a floating shield electrode and (iii) a shield electrode held at $-200 \mathrm{mV} \mathrm{vs} \mathrm{Ag} / \mathrm{AgCl}$.

\section{Significance Test for Size Distributions}

The AgNP sizes measured with a standard-MEA chip (i), a floating shield-MEA chip (ii) and a negatively-biased shield-MEA chip (iii) are $17.5 \pm 3.6 \mathrm{~nm}(\mathrm{n}=26,799), 18.2 \pm 4.3 \mathrm{~nm}(\mathrm{n}=20,479)$ and $17.0 \pm 3.6 \mathrm{~nm}(\mathrm{n}=104,712)$, respectively. By performing Welch t-tests, we find significant differences in the scores for all pairwise comparisons, (i) and (ii) $t(401,230)=-18.36, \mathrm{p}<10^{-75}$; (i) and (iii) $\mathrm{t}(408,910)=14.52$, $\mathrm{p}<10^{-50}$; (ii) and (iii) $\mathrm{t}(395,390)=32.87, \mathrm{p}<10^{-232}$. Hence, there is evidence that differently charged passivation surfaces are slightly sizediscriminant. 


\section{Particle-size Dependent Diffusive Mass Transfer}

The mass transport of AgNPs towards the detection electrodes is particle-size depended. Fig. S3 exemplarily shows the theoretical limits for the collision rate at a single microelectrodecalculated from Eqn. 3 and 4 for AgNPs with a diameter of $10 \mathrm{~nm}, 15 \mathrm{~nm}$, and $20 \mathrm{~nm}$, respectively. The effect of an altered passivation is drastically increasing for smaller particles, as depicted in Fig. S4. For instance, the mean collision rate (within the experimental time of $180 \mathrm{~s}$ ) increases approximately by a factor of 19 from $0.48 \mathrm{~Hz}$ to $9.3 \mathrm{~Hz}$ for $20 \mathrm{~nm}$-AgNPs, whereas we find a 27-fold enhancement from $0.7 \mathrm{~Hz}$ to $18.3 \mathrm{~Hz}$ for $10 \mathrm{~nm}$-sized AgNPs.

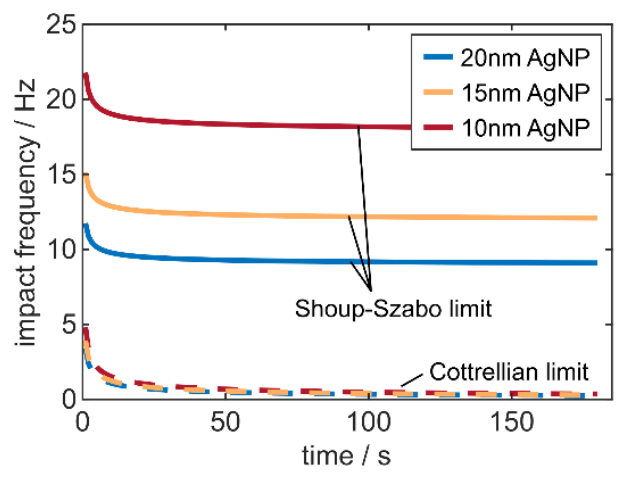

Figure S4 Theoretical impact frequencies at a single microelectrode with a radius of $4 \mu \mathrm{m}$ for a fully adsorbing boundary (dashed, Cottrellian limit, Eqn. 4) and a reflecting boundary (solid, Shoup-Szabo limit, Eqn. 3) for differently-sized AgNPs.

\section{Silver Chloride Residues}

We observe differences in the electrochemical cleaning during the recycling procedure consisting of subsequent immersions in $\mathrm{HNO}_{3}$, $\mathrm{NH}_{4} \mathrm{OH}, \mathrm{KOH}$ and $\mathrm{H}_{2} \mathrm{SO}_{4}$. Fig. S5a and $\mathrm{b}$ show the typical responses for all platinum electrodes short-circuited within the electrochemical cleaning in $100 \mathrm{mM} \mathrm{KOH}$ and $200 \mathrm{mM} \mathrm{H}_{2} \mathrm{SO}_{4}$, respectively. Additionally, the experimental data for detection experiments of chips being contaminated with $\mathrm{AgCl}$ residues is visualized. Fig. $5 \mathrm{c}$ depicts the number of detected AgNPs (measured at 62 electrodes) for successive experiments. Interestingly, there is a significant decrease if the cleaning in ammonium hydroxide $\left(\mathrm{NH}_{4} \mathrm{OH}\right)$ is left out, suggesting that the electrode area might by covered with $\mathrm{AgCl}$, thus, leading to a smaller electroactive surface. This finding is similar to the observed behavior from Compton and co-workers, when they reported differences between recordings cycles with and without mechanical cleaning in between. ${ }^{1}$

(a)

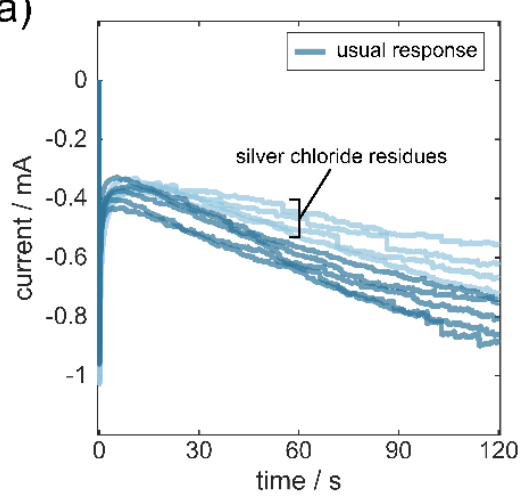

(b)

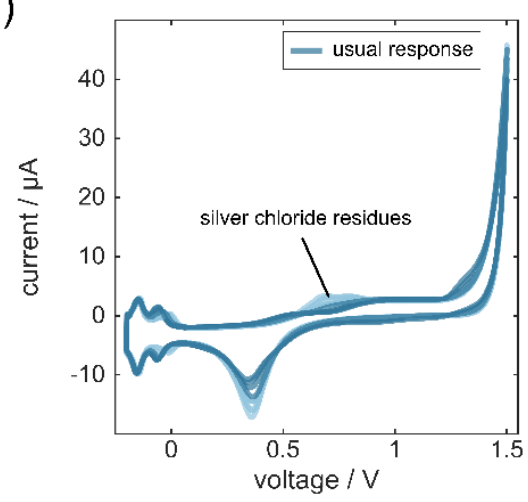

(c)

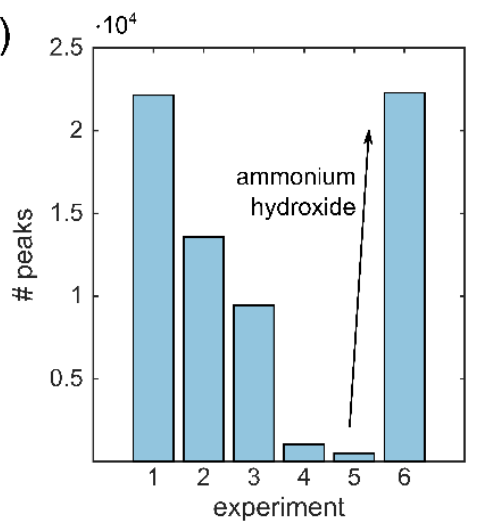

Figure S5 (a) Chronoamperometry in $100 \mathrm{mM} \mathrm{KOH}$ of all electrodes short-circuited. (b) Cyclic voltammetry in $200 \mathrm{mM} \mathrm{H}_{2} \mathrm{SO}_{4}$. (c) Number of detected peaks for subsequent detection experiments without removing silver chloride residues in between with ammonium hydroxide. The immersion in ammonium hydroxide leads to a sensor performance as before. 


\section{Aggregation of Silver Nanoparticles in $\mathrm{KCl}$ Solution}

UVvis spectra (Specord 210, analytic Jena, Jena, Germany) and DLS measurements (Zetasizer Nano ZS, Malvern Analytics, Worcestershire, $\mathrm{UK}$ ) were obtained in order to investigate changes within the AgNP ensemble in different electrolyte solutions. To this end, macro-cuvettes (PMMA, Carl Roth, Karlsruhe, Germany) were filled with $1 \mathrm{~mL}$ electrolyte, the AgNPs were subsequently inserted and mixed twice. The recordings started between 3 and $5 \mathrm{~s}$ after the insertion of AgNPs.

To investigate the effect of aggregation, we recorded within 5 min successive UV spectra from a solution containing $50 \mathrm{pM}$ AgNP (20 nm diameter) and $20 \mathrm{mM} \mathrm{KCl}$. Additionally, we investigated the temporal change in the hydrodynamic radius, obtained from DLS measurements, at different $\mathrm{KCl}$ concentrations. As shown in Fig. S6a and b, we see a slight decrease in the absorbance during a UVvis experiment indicating minor changes in the AgNP ensemble within the experimental timeframe. This finding is complemented by the DLS results in Fig. S6c, which show a significant increase in the hydrodynamic radius for $\mathrm{KCl}$ concentrations above $25 \mathrm{mM}$.

(a)

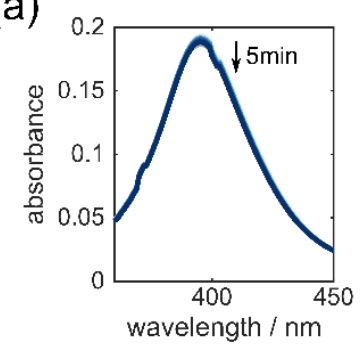

(b)

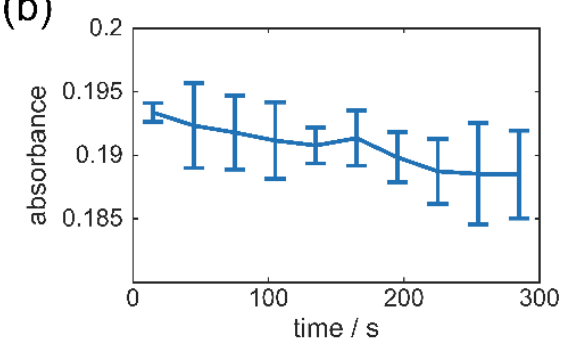

(c)

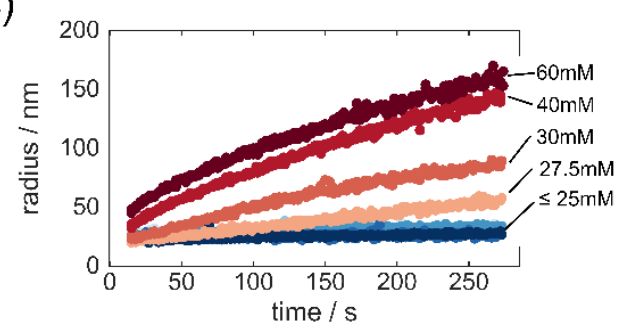

Figure S6 (a) UVvis spectra for $50 \mathrm{pM} \mathrm{AgNP} \mathrm{in} 20 \mathrm{mM} \mathrm{KCl}$ solution during $5 \mathrm{~min}$ of recording. (b) Absorbance at the peak $(\lambda=395 \mathrm{~nm})$ in (a). The sample was measured every $30 \mathrm{~s}$ after AgNP insertion for $5 \mathrm{~min}$. Error bars indicate standard deviations across 3 trials. (c) Temporal change in the hydrodynamic radius obtained from DLS measurements in case of $500 \mathrm{pM} \mathrm{AgNP}$ with $20 \mathrm{~nm}$ size for various $\mathrm{KCl}$ concentrations.

\section{References}

(1) Batchelor-McAuley, C.; Ellison, J.; Tschulik, K.; L. Hurst, P.; Boldt, R.; G. Compton, R. In Situ Nanoparticle Sizing with Zeptomole Sensitivity. Analyst 2015, 140 (15), 5048-5054. https://doi.org/10.1039/C5AN00474H. 